\title{
COMPARING THE RESULTS OF THE URICA AND THE TMQ TO DETERMINE THE EFFECT OF CONTINGENCY MANAGEMENT INTERVENTION ON INTRINSIC MOTIVATION
}

\author{
Mohamad Salleh Abdul Ghani ${ }^{1 *}$, Mohamad Isa Amat ${ }^{2}$, \\ Haslee Sharil Lim Abdullah ${ }^{3}$
}

\footnotetext{
${ }^{*} \mathrm{PhD}$ candidate at the Faculty of Leadership and Management, Universiti Sains Islam Malaysia, Malaysia.

${ }^{2}$ Associate researcher at the Asian Centre for Research on Drug Abuse (ACREDA) and a senior lecturer in the Faculty of Leadership and Management, Universiti Sains Islam Malaysia, ${ }^{3}$ Professor at the Faculty of Leadership and Management, Universiti Sains Islam Malaysia, Malaysia.
}

\begin{abstract}
The objective of the study was to determine whether contingency management (CM) intervention also known as motivational incentive influences intrinsic motivation of clients in an institutionalized drug treatment centre. A Randomized controlled trial design was used in this study involving random assignment of subjects into experimental and controlled groups. A total of 44 clients were divided into two groups namely the experimental group who received the usual program with $\mathrm{CM}$ intervention $(\mathrm{CM})$ and the control group receiving only the usual program (TAU). CM interventions are administered from the beginning of the first week to week 12th and terminated on the 13th to 16th week to observe the follow-up effect of CM's effectiveness on client motivation. CM interventions used in this study via sticker chart rewards system where every achieved positive behaviour changes in the treatment session will be rewarded with a reward sticker which will be put on the clients' achievement chart. The sticker has a certain monetary value that can be exchanged with privileges or certain items. Experimental groups received CM rewards while no rewards are given to the control group. To measure the client's motivation level, two standardize instrument was used which was the University of Rhode Island Change Assessment (URICA) and the Treatment Motivation Questionnaire (TMQ). Qualitative data was also collected through a semi-structured interview to gain an in-depth input on the effectiveness of CM toward the client's intrinsic motivation as well as to determine the consistency of the quantitative findings. The results showed that $\mathrm{CM}$ effective in improving the intrinsic motivation of the clients towards the treatment programs. Results of the interview showed that most clients felt that CM helped increase their selfmotivation to participate in the treatment session and enhance their spirit to implement the knowledge learned from the treatment session.
\end{abstract}

Keywords: Contingency management, substance use disorders, intrinsic motivation, Treatment Motivation Questionnaire, Stages of Change 


\section{Introduction}

Substance use disorders correspond to an extremely widespread and costly public health problem in Malaysia and most other developed and developing countries (Ali, Hassan, \& Karim, 2009; UNODC, 2016). The need for greater scientific understanding of SUDs as well as effective interventions for preventing and treating these disorders is immense. The field of behaviour analysis has made numerous contributions to a scientific analysis of SUDs. Among those contributions was the use of contingency management $(\mathrm{CM})$ to treat SUDs (Higgins \& Silverman, 2008).

Contingency management (CM) intervention is an evidence-based approach that is currently being considered in Malaysia. Previous studies on CM has shown CM to be effective in developing behaviour changes among drug addicts (Davis et al., 2016; Hartzler, Lash, \& Roll, 2012; Rohsenow, 2008). CM involves the systematic application of reinforcing outcomes to promote and sustain positive behaviour change. CM interventions focus not only on increasing abstinence from drug use, but also on increasing clinic attendance, adherence with medication regimens, and other therapeutic targets such as vocational goals (Higgins \& Silverman, 2008). CM is designed based on the principles to establish a behaviour using positive reinforcement similar to drugs reinforce substance use. CM treatment rearranges the environment to directly detect drug use and encourage patient participation in activities that promote recovery (Higgins, Heil, \& Sigmon, 2013; Petry, 2000). In most CM studies, reinforcement was given in the form of vouchers that can be redeemed with daily items, facilities and special privileges in the treatment settings (Higgins, Alessi, \& Dantona, 2002).

In the field of SUDs treatment and rehabilitation, motivation to change has been a major focus of attention in determining the failure or a success of any intervention. Motivation has been described as a prerequisite for treatment, if clients lack in motivation, less can be done by the clinician to help them (Beckman, 1980). Motivation has shown to be highly correlated with treatment engagement, maintenance and compliance with treatment. High motivation has shown to predict retention, lower relapse rates, and produce better treatment outcomes (Smith, 2016). In a research conducted by Wild, Yuan, Rush, \& Urbanoski (2016) found that clients with a low level of internal motivation at admission were likely to exhibit early dropout meanwhile, clients who reported high admission levels of intrinsic motivation were most likely to remain in treatment with high cognitive involvement.

The previous finding on the effects of rewards on intrinsic motivation is often based on the cognitive evaluation theory (Deci \& Ryan, 1985; Ryan \& Deci, 2000). This theory proposes that intrinsic motivation is needed for any behaviour change to be sustained and that external rewards weaken or lower the intrinsic motivation of an individual. The theory also suggests that intrinsic motivation can be increased by enhancing the feelings of competence, autonomy, and self-determination (Deci \& Ryan, 1985; Ryan \& Deci, 2000). Cognitive evaluation theorists argue that external rewards reduce feelings of competence, autonomy, and self-determination because they shift the locus of causality from factors internal to the individual to factors external to the individual (Deci \& Ryan, 1985; Ryan \& Deci, 2000). Furthermore, the reason that although rewards can change behaviour initially, once they are removed, the behaviour will return to baseline levels because individuals are not intrinsically motivated to maintain the 
behaviour change (Deci, Koestner, \& Ryan, 1999).

The results from previous studies indicate that rewards used in CM interventions do not necessarily undermine intrinsic motivation (Budney, Higgins, Radonovich, \& Novy, 2000; Ledgerwood \& Petry, 2006). CM intervention conducted in psychosocial treatment settings has specifically assessed the influence of $\mathrm{CM}$ on patients' intrinsic motivation to change substance use measured using the University of Rhode Island Change Assessment (URICA) (Budney et al., 2000). There are a few limitations regarding the use of URICA in measuring intrinsic motivation in previous CM studies (Walter \& Petry, 2014). One limitation in the use of URICA was the instrument may be problematic and confusing for clients who have experienced sustained periods of abstinence especially those who have been in treatment for sometimes. Many of the items are more relevant to the client before they enter treatment rather than already receiving one. Clients that are currently in treatment especially in an institutionalized setting cannot respond appropriately to some items on the maintenance and action subscale of the instrument because of the confusing question asked such as item like "It worries me that I might slip back on a problem I have already changed, so I am here to seek help" and "I'm not following through with what I already changed as well as I had hoped, and I'm here to prevent a relapse of the problem" (Walter \& Petry, 2016). Previous study has shown that CM does affect clients' intrinsic motivation, but because of issues regarding the URICA, it is difficult to determine whether the results are valid enough.

Thus, this study would like to further investigate the effect of $\mathrm{CM}$ on intrinsic motivation using URICA and supported with two other instrument using the Treatment Motivation Questionnaire (TMQ) (Cahill, Adinoff, Hosig, Muller, \& Pulliam, 2003; Ryan, Plant, \& O'Malley, 1995; Zeldman, Ryan, \& Fiscella, 2004) and a semi-structured interview. The objective of this study was to find out whether CM can affect clients' motivation especially intrinsic motivation and also to find out whether this study produces similar results made by Budney et al., (2000) and Ledgerwood \& Petry, (2006) using three methods of assessment.

\section{Methodology}

\subsection{Research Design}

This study used a randomized controlled trial design involving random assignment of participants into two groups. 44 clients were assigned randomly into two groups of an experimental and controlled group using excel random number generator. The clients in the experimental group received the usual treatment program with $\mathrm{CM}$ intervention $(\mathrm{CM})$. Meanwhile, the control group received only the treatment as usual program (TAU). The CM group were exposed to the treatment for 12 weeks and continue with the treatment for another four weeks without CM intervention for follow up study. For the TAU groups, they received the usual psychosocial program for the full 16 weeks. A weekly assessment was done to measure treatment engagement, meanwhile, for the treatment motivation, an assessment was done at the three-time point of pre, post, and one month follow up. A semi-structured interview was also done among the clients in order to better understand and to see the consistency from 


\section{1 - 23 JUNE 2019 \\ VIENNA, AUSTRIA}

what has been identified in the quantitative analysis of the effectiveness of CM on the client's intrinsic motivation.

\subsection{Participants}

A total of 94 CCRC clients were recruited to join the study. From the total screened, 44 clients met with the inclusion criteria and selected as participants in the study. The participants were selected based on the following criteria: entering CCRC for the first time; aged between 19 to 39 years old; participate in psychosocial programs; be able to read and write; male; Malay ethnicity; and did not have any form of psychiatric disorder or chronic disease; did not take part in any drug substitution therapy, and; agree to join the research. Purposive sampling was used for the semi-structured interview and the researcher interviewed seven participants determine by the point of saturation in the study (Boyd, 2001). Every necessary requirement regarding the ethical aspects of the study had been dealt with and explained to the participants accordingly prior to the study. The Universiti Sains Islam Malaysia's ethics board committee has accepted and granted approval on the implementation of this study (USIM/JKEP/2018-35).

\subsection{CM intervention}

The institutionalized treatment centre also known as the Cure and Care Rehab Centre (CCRC)'s treatment program consists of the psychosocial session which combined components of relapse prevention, cognitive behavioural therapy, psycho-education, family intervention approaches, and the 12-steps program. This evidence-based program has been adopted and adapted into Malaysian addiction treatment setting and has been found effective for the clients' recovery (Mohamed, Zakaria, \& Hj Ghani, 2009). CM intervention in this study was combined with the psychosocial session conducted on a weekly basis. CM reinforcement were given to reinforce positive behaviour based on achieved targeted goal related to treatment engagement such as completion of homework/ assignment, active participation in the treatment session, and performance in the weekly quizzes during treatment session using reward sticker based on Bartholomew, Rowan-Szal, \& Simpson, (2005) and CM protocol by Petry, (2000). Each reward stickers have a monetary value which can be exchanged for certain items such as fast food, toiletries, books and clothing items. The value of each sticker begins with MYR2.00 and increase every four weeks to the value of MYR5.00 per stickers. Each person can get a maximum of three stickers every week and can earn a maximum value of MYR15.00 every week. The client who collected the most stickers after every four weeks get a bonus sticker equivalent to MYR10.00. Measurement using questionnaire was taken three times during the course of the research, first will be during the initial study of pre-test, the second is the posttest which will be collected after week $12^{\text {th }}$ and another test will be collected as a follow-up test, which will be done one month after the intervention stopped. A semi-structured interview also conducted during the end of the follow-up test.

\subsection{Instruments}


To measure the clients' motivation, two standardize questionnaire was used namely The University of Rhode Island Change Assessment (URICA) and the Treatment Motivation Questionnaire (TMQ). The URICA provides an assessment of readiness to change a problem behaviour and has demonstrated strong psychometric properties. This 32-item instrument includes four subscales designed to operationally define four theoretical stages: precontemplation, contemplation, action, and maintenance (DiClemente, Schlundt, \& Gemmell, 2004). Clients respond to each item using a five-point Likert scale ranging from 1 (strongly disagree) to 5 (strongly agree). Each subscale has shown good internal consistency (DiClemente \& Hughes, 1990; Prochaska, DiClemente, \& Norcross, 1992). A readiness composite (RC) score was used as an overall measure of readiness for change (Project Match Group, 1997). The $\mathrm{RC}$ is the sum of the contemplation, action and maintenance sub-scales of the URICA minus the pre-contemplation sub-scale. Higher scores on the RC represent greater motivation to change substance use and higher intrinsic motivation.

Another standardize instrument used was the Treatment Motivation Questionnaire (TMQ) (Cahill et al., 2003; Ryan et al., 1995; Zeldman et al., 2004) which comprises of 26 items with four sub-scales namely (a) internal, (b) external, (c) help-seeking, and (d) confidence in treatment. The TMQ used a Likert score of (1) being 'not at all true' to (7) being 'very true'. For the purpose of this research, the researcher focusses and report only one of the TMQ subscale namely the 'internal motivation' which relate directly to intrinsic motivation of the client. Both questionnaires were translated into Malay language using 'back to back translation' and a pilot test conducted found it to have high reliability of Cronbach's alpha above .70 for all subscale on both instruments.

The semi-structured interview performed to gather information that was missed by the researcher using the standardized questionnaire. Additional information was acquired in order to further support the finding of the qualitative data (Saunders, Lewis, \& Thornhill, 2009). Opened and closed-ended questions were used in the interview which allows the client to tell, describe and to confirm certain fact or information freely with minimum controlled by the researcher (Saunders et al., 2009).

\subsection{Data Analysis}

Intention to treat analysis (ITT) were used in this study to avoid the risk of non-random attrition of participants and to provide unbiased comparisons among the treatment groups. Blinding were performed on both treatment group to avoid the issue of rewards rivalry and compensation between both groups. Statistical software IBM-SPSS (version 22 for Windows) was used to analyse the data. Group comparison for baseline characteristic was done using $a t$ test, for continuous data, a chi-square $(\chi 2)$ test was calculated for nominal and categorical data. Repeated measure ANOVA (RM ANOVA) was used to measure the clients' motivation using the URICA and TMQ. 


\author{
21 - 23 JUNE 2019 \\ VIENNA, AUSTRIA
}

\title{
3. Findings
}

\subsection{Baseline Characteristics}

Socio-demographic characteristic of the 44 clients is based on the inclusion criteria determined by the researcher. A few added information was also included such as level of education, marital status, and occupational information to further explore the background of the clients. Overall, the average age of the clients is 28 years old with Malay ethnicity and Islam in religion. Around 50\% (CM) to 65\% (TAU) have an education level of Higher Learning Certificate (SPM). More than $60 \%$ of them are single and less than $20 \%$ of them previously had a job with an average income of RM1500 to RM2200 (Table 1). Clinical characteristic at baseline showed an average substance use starting at the age of 23 years old for the CM group and at 24 years old in the TAU group with a period of addiction of 4 to 5 years. Reason for drugs use was difference between both groups with $50 \%$ of the CM group are caused by peer influence and $61 \%$ from the TAU group, because of curiosity to try. All clients entered the CCRC for treatment for the first time and were all methamphetamine user. Comparison between both groups showed that both groups are similar which proved that randomization has succeeded.

Table 1: Baseline Demographic Characteristics

\begin{tabular}{|c|c|c|}
\hline $\operatorname{Variables}^{\mathrm{a}}(N=44)$ & $\begin{array}{c}\text { TAU } \\
\text { (controlled group) } \\
(N=22)\end{array}$ & $\begin{array}{c}\mathrm{CM} \\
\text { (experimental group) } \\
(N=22)\end{array}$ \\
\hline Gender ( $\%$ male $)$ & 100 & 100 \\
\hline Age & $28.9(4.8)$ & $28.7(4.6)$ \\
\hline Ethnicity (\% Malays) & 95.7 & 100 \\
\hline Religion (\% Islam) & 100 & 100 \\
\hline \multicolumn{3}{|l|}{ Education level (\%) } \\
\hline - Diploma & 0 & 9.1 \\
\hline - SPM & 65.2 & 50 \\
\hline - $\quad$ PMR & 21.7 & 27.3 \\
\hline - $\quad$ Primary School & 13.0 & 13.6 \\
\hline \multicolumn{3}{|l|}{ Marital status (\%) } \\
\hline - single & 61 & 68 \\
\hline - married & 30 & 32 \\
\hline - $\quad$ divorced & 9 & 0 \\
\hline Occupation status (\% working) & 21 & 16 \\
\hline Drug use starting age & $24.3(5.2)$ & $23.4(5.3)$ \\
\hline Period of addiction & $4.1(2.0)$ & $4.9(2.7)$ \\
\hline \multicolumn{3}{|l|}{ Reason for using (\%) } \\
\hline - peer influence & 34.8 & 50 \\
\hline
\end{tabular}




\begin{tabular}{lcc}
\hline - curiosity & 61 & 41 \\
$-\quad$ family problems & 4.3 & 4.5 \\
$-\quad$ others & 0 & 4.5 \\
Type of drug used (\% meth) & 100 & 100 \\
The severity of dependence scale (SDS) & $1.3(0.4)$ & $1.4(0.6)$ \\
URICA RC & $9.31(1.24)$ & $9.76(1.92)$ \\
Treatment Motivation (TMQ) & $5.05(0.80)$ & $5.0(0.79)$ \\
$-\quad$ Internal Motivation & $5.41(1.11)$ & $5.3(1.10)$ \\
\hline
\end{tabular}

${ }^{a}$ Values are mean (SD), otherwise declared.

\subsection{URICA RC results}

The results of a One-Way Repeated Measures ANOVA on the URICA RC score showed that $\mathrm{CM}$ had a significant effect toward clients' readiness to change at three-time point $(F(2$, $84)=7.51, \mathrm{p}<.001$ ), which showed an increase of motivation to change within time for both groups. However, the results showed no significant effect between TAU and CM treatment group $(F(1,42)=0.58, \mathrm{p}>.05)$. Partial Eta Squared effect size for time was $\left(\eta_{\mathrm{p}}{ }^{2}=.152\right)$ indicated that time had a large effect size for all the clients. Although the result showed that CM group have a higher mean score compared to the TAU, the differences are not statistically significant which indicate CM does not significantly affect clients' readiness to change (figure 1).

Table 2: URICA RC score at pre, post and follow-up test

\begin{tabular}{ccccccc}
\hline \multirow{2}{*}{ Group } & \multicolumn{2}{c}{ RC pre } & \multicolumn{2}{c}{ RC post } & \multicolumn{2}{c}{ RC follow-up } \\
\cline { 2 - 7 } & Mean & S.D & Mean & S.D & Mean & S.D \\
\hline CM & 9.77 & 1.92 & 10.16 & 1.61 & 10.90 & 1.96 \\
TAU & 9.31 & 1.24 & 9.96 & 2.24 & 10.60 & 1.84 \\
\hline
\end{tabular}

Figure 1: RC score between CM and TAU group at pre, post and follow up test

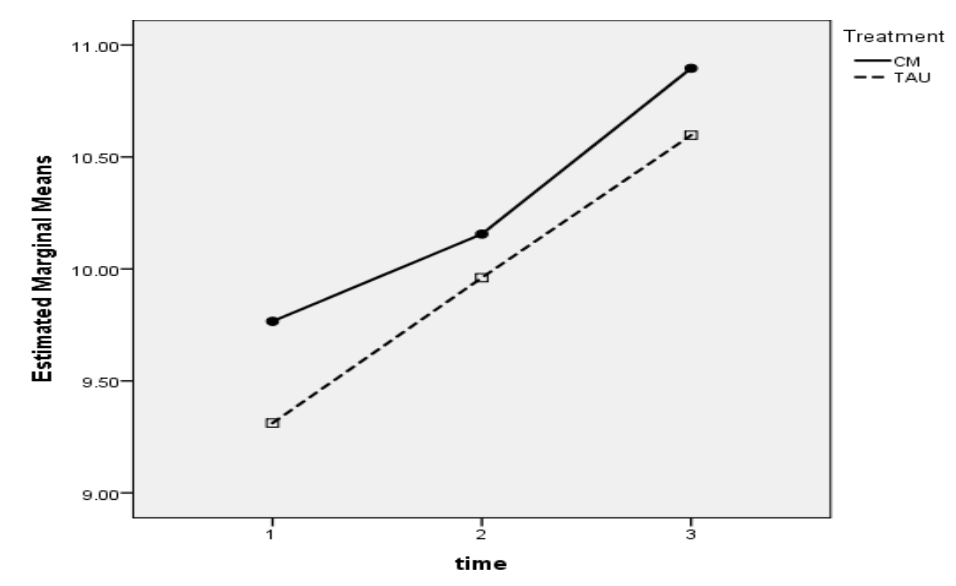

\subsection{TMQ Composite results}

TMQ composite score was analysed to measure the overall treatment motivation of the clients at the three-time point of pre, post and follow up at one month after the intervention. The results of a One-Way Repeated Measures ANOVA show that CM has a significant effect 
toward treatment motivation at the three time points of pre, post and follow up (within subjects effects) $F(1.68,70.75)=14.37, \mathrm{p}<.001$ and there was also a significant difference between treatment groups (between subjects effect) $F(1,42)=4.46$, p<.005. Partial Eta Squared effect size for the three-time point was $\left(\eta_{\mathrm{p}}^{2}=.255\right)$ and for the treatment effect was $\left(\eta_{\mathrm{p}}{ }^{2}=.0 .96\right)$ indicated that $\mathrm{CM}$ had a substantial effect for time and a medium effect on treatment groups (figure 2).

Table 3: TMQ score at pre, post and follow-up test

\begin{tabular}{ccccccc}
\hline \multirow{2}{*}{ Group } & \multicolumn{2}{c}{ TMQ pre } & \multicolumn{2}{c}{ TMQ post } & \multicolumn{2}{c}{ TMQ follow-up } \\
\cline { 2 - 7 } & Mean & S.D & Mean & S.D & Mean & S.D \\
\hline CM & 5.00 & 0.79 & 5.73 & 0.27 & 5.88 & 0.60 \\
TAU & 5.05 & 0.80 & 5.27 & 0.54 & 5.51 & 0.71 \\
\hline
\end{tabular}

Figure 2: TMQ score between CM and TAU group at pre, post and follow up test

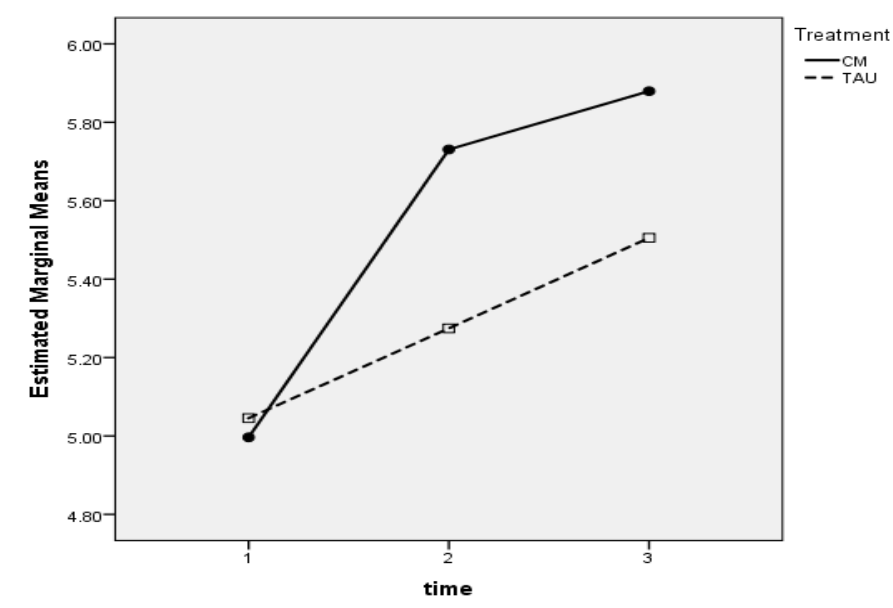

\subsection{Intrinsic Motivation}

The results of a One-Way Repeated Measures ANOVA showed that CM had a significant effect toward clients' internal motivation at the three-time point $(F(1.552,65.168)=9.989$, $\mathrm{p}<.001)$ and a significant between-group effect $(F(1,42)=6.69, \mathrm{p}<.05)$. Partial Eta Squared effect size for the three-time point was $\left(\eta_{\mathrm{p}}{ }^{2}=.192\right)$ and for the treatment effect was $\left(\eta_{\mathrm{p}}{ }^{2}=.137\right)$ indicated that $\mathrm{CM}$ had a large effect size for both time and treatment groups. The estimated marginal means of the clients' internal motivation showed that both groups had an upward trend. However, the TAU+CM group had higher significant differences between the TAU group especially when CM intervention was administered at post-test (Figure 3).

Table 4: Intrinsic motivation score at pre, post and follow-up test

\begin{tabular}{|c|c|c|c|c|c|c|}
\hline \multirow{2}{*}{ Group } & \multicolumn{2}{|c|}{ Intrinsic pre } & \multicolumn{2}{|c|}{ Intrinsic post } & \multicolumn{2}{|c|}{ Intrinsic follow-up } \\
\hline & Mean & S.D & Mean & S.D & Mean & S.D \\
\hline
\end{tabular}


21 - 23 JUNE $2019 \quad$ VIENNA, AUSTRIA

\begin{tabular}{ccccccc}
\hline CM & 5.30 & 1.08 & 6.33 & 0.33 & 6.40 & 0.53 \\
TAU & 5.41 & 1.11 & 5.47 & 0.84 & 5.91 & 1.06 \\
\hline
\end{tabular}

Figure 3: Intrinsic motivation between TAU+CM group and TAU group at the three-time point

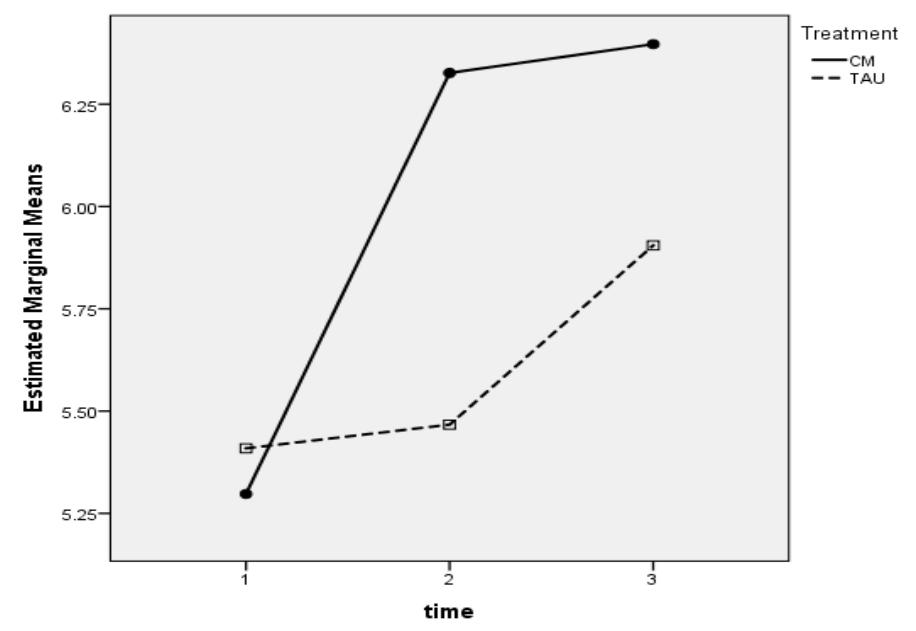

\subsection{Results of the Semi-Structured Interview}

A semi-structured interview was conducted on seven clients based on the saturation point reached at six clients. From the interview, we found that all clients mentioned that while the reward itself is helpful as an added incentive for them, they felt that they were not really after the reward itself but rather the knowledge that they have acquired during their classes are more important. For them, the reward was just addition and that their motivation to change increased regardless of the rewards. All participants mentioned that they have realized their past mistakes during their $\mathrm{CM}$ therapy sessions. They reported that $\mathrm{CM}$ provides them strength within themselves to change their lifestyle and behaviour after leaving the rehabilitation centre. The rewards have given them extra encouragement to change their addiction patterns. five out of seven clients find more strength to change their addictive behaviour and feel more confident to apply the knowledge learned in the treatment session. One of the clients stated that the rewardbased system has made him realize that he can still change despite his previous addiction to meth. Six out of seven clients shared that they have positive feelings and looking forward to attending each treatment session and motivated to implement their recovery knowledge outside the CCRC.

\section{Discussion}

The finding of this study showed that assessment using the URICA RC found that CM intervention does not has a significant effect on intrinsic motivation due to certain issues with the instrument which resulted in the finding found to be non-significant. However, assessment using the TMQ found CM to have a significant effect on clients' intrinsic motivation. The conflicting results are not surprising due to the problematic and confusing item discussed by 
Walter and Petry, (2016). Even though there are mean differences showed between both experimental groups, the $\mathrm{CM}$ group shown to have a higher intrinsic motivation compared to the TAU group. The finding using URICA RC did not support the finding made by Budney et al., (2000) and Ledgerwood \& Petry, (2006), however, TMQ analysis using the internal subscale found CM interventions to have a significant effect on the clients' intrinsic motivation.

The use of TMQ Internal motivation was found to be more accurate based on the clients' background and setting in a treatment centre. Although the result between both instruments seems to show a different outcome, the used of a semi-structured interview has helped in clarifying the result of this study. The finding made from the semi-structured interview supported the significant result of the TMQ. Based on the interview, most clients felt that CM does improve their intrinsic motivation to change their addictive behaviour and implementing the recovery knowledge gain in the session. This significant finding are similar to the finding made by Budney et al., (2000) and Ledgerwood \& Petry, (2006) and also consistent with study conducted by Cameron, Banko, \& Pierce, (2001) and Promberger \& Marteau, (2013) which states that external rewards can also increase intrinsic motivation. Cameron et al., (2001) in her study on the effect of rewards on intrinsic motivation believes that rewarding clients for their accomplishment in a low-interest task such as related to treatment and rehabilitation helped improve intrinsic motivation in the long run by cultivating interest toward the activity after they have experienced the positive effect of the task.

This finding also refutes the views of (Deci, Koestner, \& Ryan, 1999) which believe that an individual is not intrinsically motivated through rewards and behaviours will return to the original form after the reward is stopped and also finding by Carroll, Sinha, Nich, Babuscio, and Rounsaville, (2002) who found that clients assigned to CM experienced a decrease in motivation while those in the non-CM condition experienced an increase. This difference may be due in part to differences between the samples. Carroll et al. (2002) studied detoxified opioid patients seeking naltrexone treatment, a sample who may experience a higher initial motivation than the community sample initiating drug abuse treatment in the current study.

\section{Limitation and suggestion}

$\mathrm{CM}$ is still new in the field of SUD's treatment and rehabilitation in Malaysia, one of the obstacles that researchers face in conducting this study was the lack of reference in the local context primarily in determining the appropriate magnitude for CM reinforcer. Petry, Alessi, Barry, and Carroll, (2015) found that the standard magnitude of \$ 300 was also found to be efficacious compared to a higher magnitude of $\$ 900$. Some studies also suggest that increasing the magnitude of reinforcer can improve the effectiveness of CM (Ghitza, Epstein, \& Preston, 2008). Previous studies in the west and developed countries do not fit as a guideline to determine the magnitude of CM reinforcer in the local context of Malaysia for this study. Another limitation of the study was the sample size for this study was still considered as small to be generalizing the effect of CM in a larger perspective. Larger sample sizes are suggested to obtain more accurate and comprehensive findings on CM effectiveness. 


\author{
21 - 23 JUNE $2019 \quad$ VIENNA, AUSTRIA
}

\title{
6. Conclusion
}

$\mathrm{CM}$ is an evidence-based intervention that can enhance clients' intrinsic motivation toward treatment programs. It proved that CM intervention are suitable and can be implemented in the treatment of SUDs in this country. This study not only provides input from the Malaysian perspective but also helps broaden the knowledge of local addiction professionals in implementing the various approaches of treatment and rehabilitation. These evidence-based approaches will help addiction professionals in Malaysia to have more experience and intervention alternatives to suit better with their clients' treatment requirement thus making recovery more effective.

\section{Acknowledgement}

The author would like to acknowledge the Malaysia's National Anti-Drugs Agency (NADA) for funding this academic research (USIM/AADK/FKP/052003/43317). The researcher would also like to thank the staff and clients of CCRC Dengkil for their assistant and cooperation during the period of study.

\section{References}

[1] Ali, J., Hassan, S., \& Karim, N. A. A. (2009). Kos Ekonomi Penyalahgunaan Dadah. Jurnal Antidadah Malaysia, 6(5), 107-121.

[2] Bartholomew, N. G., Rowan-Szal, G. A., \& Simpson, D. D. (2005). Contingency Management Strategies and Ideas: A Planning guide for using rewards and start charts to reinforce goal setting, early engagement in treatment settings.

[3] Beckman, L. J. (1980). An attributional analysis of Alcoholics Anonymous. Journal of Studies on Alcohol, 41(7), 714-726. Retrieved from http://www.ncbi.nlm.nih.gov/pubmed/7421260

[4] Budney, a J., Higgins, S. T., Radonovich, K. J., \& Novy, P. L. (2000). Adding voucherbased incentives to coping skills and motivational enhancement improves outcomes during treatment for marijuana dependence. Journal of Consulting and Clinical Psychology, 68(6), 1051-1061. https://doi.org/10.1037/0022-006X.68.6.1051

[5] Budney, A. J., Higgins, S. T., Radonovich, K. J., \& Novy, P. L. (2000). Adding voucherbased incentives to coping skills and motivational enhancement improves outcomes during treatment for marijuana dependence. Journal of Consulting and Clinical Psychology, 68(6), 1051-1061. https://doi.org/10.1037/0022-006X.68.6.1051

[6] Cahill, M. A., Adinoff, B., Hosig, H., Muller, K., \& Pulliam, C. (2003). Motivation for treatment preceding and following a substance abuse program. Addictive Behaviors, 28(1), 67-79. https://doi.org/10.1016/S0306-4603(01)00217-9

[7] Cameron, J., Banko, K. M., \& Pierce, W. D. (2001). Pervasive Negative Effects of Rewards on Intrinsic Motivation: The Myth Continues. The Behavior Analyst, 24(1), 144. Retrieved from http://www.behavior.org/resources/331.pdf

[8] Carroll, K. M., Sinha, R., Nich, C., Babuscio, T., \& Rounsaville, B. J. (2002). Contingency management to enhance naltrexone treatment of opioid dependence: A randomized clinical trial of reinforcement magnitude. Experimental and Clinical 


\section{1 - 23 JUNE $2019 \quad$ VIENNA, AUSTRIA}

Psychopharmacology, 10(1), 54-63. https://doi.org/10.1037/1064-1297.10.1.54

[9] Davis, D. R., Kurti, A. N., Skelly, J. M., Redner, R., White, T. J., \& Higgins, S. T. (2016). A review of the literature on contingency management in the treatment of substance use disorders, 2009-2014. Preventive Medicine, 92, 36-46. https://doi.org/10.1016/j.ypmed.2016.08.008

[10] Deci, E. L., Koestner, R., \& Ryan, R. M. (1999). A meta-analytic review of experiments examining the effects of extrinsic rewards on intrinsic motivation. Psychological Bulletin, 125(6), 627-668. https://doi.org/10.1037/0033-2909.125.6.627

[11] Deci, E. L., Koestner, R., \& Ryan, R. M. (1999). A meta-analytic review of experiments examining the effects of extrinsic rewards on intrinsic motivation. Psychological Bulletin, 125(6), 627-68; discussion 692-700. https://doi.org/10.1037/0033-2909.125.6.627

[12] Deci, E., \& Ryan, R. (1985). Intrinsic motivation and self-determination in human behaviour. New York: Plenum. https://doi.org/10.1017/CBO9781107415324.004

[13] DiClemente, C. C., \& Hughes, S. O. (1990). Stages of change profiles in outpatient alcoholism treatment. Journal of Substance Abuse, 2(2), 217-235. https://doi.org/10.1016/S0899-3289(05)80057-4

[14] DiClemente, C. C., Schlundt, D., \& Gemmell, L. (2004). Readiness and Stages of Change in Addiction Treatment. American Journal on Addictions, 13(2), 103-119. https://doi.org/10.1080/10550490490435777

[15] Ghitza, U. E., Epstein, D. H., \& Preston, K. L. (2008). Contingency management reduces injection-related HIV risk behaviors in heroin and cocaine using outpatients. Addictive Behaviors, 33(4), 593-604. https://doi.org/10.1016/j.addbeh.2007.11.009

[16] Hartzler, B., Lash, S. J., \& Roll, J. M. (2012). Contingency management in substance abuse treatment: A structured review of the evidence for its transportability. Drug and Alcohol Dependence, 122(1-2), 1-10. https://doi.org/10.1016/j.drugalcdep.2011.11.011

[17] Higgins, S. T., Alessi, S. M., \& Dantona, R. L. (2002). Voucher-based incentives: A substance abuse treatment innovation. Addictive Behaviors, 27(6), 887-910. https://doi.org/10.1016/S0306-4603(02)00297-6

[18] Higgins, S. T., Heil, S. H., \& Sigmon, S. C. (2013). Voucher-based contingency management in the treatment of substance use disorders. APA Handbook of Behavior Analysis, Vol. 2: Translating Principles into Practice., 2, 481-500. https://doi.org/10.1037/13938-019

[19] Higgins, S. T., \& Silverman, K. (2008). Contingency management. In The American Psychiatric Publishing textbook of substance abuse treatment (4th ed.) (pp. 387-399).

[20] Ledgerwood, D. M., \& Petry, N. M. (2006). Does contingency management affect motivation to change substance use? Drug and Alcohol Dependence, 83(1), 65-72. https://doi.org/10.1016/j.drugalcdep.2005.10.012

[21] Mahmood Nazar Mohamed, Zakaria, M., \& Hj Ghani, S. (2009). Keberkesanan Modul Model Matrix Untuk Pemulihan Penagih Dadah Dalam Setting Komuniti. Jurnal Antidadah Kebangsaan, 6(2). Retrieved from https://www.adk.gov.my/wpcontent/uploads/jurnal_3.pdf

[22] Match, P. (1997). Matching Alcoholism Treatments to Client Heterogeneity. Journal of Studies on Alcohol, 58(1), 7-29. https://doi.org/10.15288/jsa.1997.58.7

[23] Petry, N. M. (2000). A comprehensive guide to the application of contingency management procedures in clinical settings. Drug and Alcohol Dependence, 58, 9-25. 
https://doi.org/10.1016/S0376-8716(99)00071-X

[24] Petry, N. M., Alessi, S. M., Barry, D., \& Carroll, K. M. (2015). Standard magnitude prize reinforcers can be as efficacious as larger magnitude reinforcers in cocaine-dependent methadone patients. Journal of Consulting and Clinical Psychology, 83(3), 464-472. https://doi.org/10.1037/a0037888

[25] Prochaska, J. O., DiClemente, C. C., \& Norcross, J. C. (1992). In search of how people change Applications to addicitive behaviors. American Psychologist, 49(9), 1102-1114. https://doi.org/10.1037/0003-066X.47.9.1102

[26] Promberger, M., \& Marteau, T. M. (2013). When do financial incentives reduce intrinsic motivation? Comparing behaviors studied in psychological and economic literatures. Health Psychology, 32(9), 950-957. https://doi.org/10.1037/a0032727

[27] Rohsenow, D. (2008). Contingency Management in Substance Abuse Treatment. Social Service Review (Vol. 82). https://doi.org/10.1086/595875

[28] Ryan, R. M., \& Deci, E. L. (2000). Intrinsic and Extrinsic Motivations: Classic Definitions and New Directions. Contemporary Educational Psychology, 25(1), 54-67.

[29] Ryan, R. M., Plant, R. W., \& O’Malley, S. (1995). Initial motivations for alcohol treatment: relations with patient characteristics, treatment involvment, and dropout. Addictive Behaviors, 20(3), 279-297.

[30] Saunders, M., Lewis, P., \& Thornhill, A. (2009). Research Methods for Business Students. Research methods for business students (5th ed.). Edinburgh Gate: Pearson Education. https://doi.org/10.1007/s13398-014-0173-7.2

[31] Smith, D. J. (2016). Substance Abuse Treatment Motivation: A Self-Determination Theory Perspective of Probation and Parole Clients. Retrieved from http://search.proquest.com/openview/07f3fa0a78269cf142ca1b86f4acaca3/1?pqorigsite $=$ gscholar $\& \mathrm{cbl}=18750 \&$ diss $=\mathrm{y}$

[32] UNODC. (2016). World Drug Report 2016. New York. Retrieved from http://www.unodc.org/doc/wdr2016/WORLD_DRUG_REPORT_2016_web.pdf

[33] Walter, K. N., \& Petry, N. M. (2014). Patients with diabetes respond well to contingency management treatment targeting alcohol and substance use. Psychology, Health \& Medicine, 8506(February 2015). https://doi.org/10.1080/13548506.2014.991334

[34] Walter, K. N., \& Petry, N. M. (2016). Motivation and contingency management treatments for substance use disorders. Current Topics in Behavioral Neurosciences, 27, 569-581. https://doi.org/10.1007/7854_2015_374

[35] Wild, T. C., Yuan, Y., Rush, B. R., \& Urbanoski, K. A. (2016). Client engagement in legally-mandated addiction treatment: A prospective study using self-determination theory. Journal of Substance Abuse Treatment, 69, 35-43. https://doi.org/10.1016/j.jsat.2016.06.006

[36] Zeldman, A., Ryan, R. M., \& Fiscella, K. (2004). Motivation, autonomy support, and entity beliefs: Their role in methadone maintenance treatment. Journal of Social and Clinical Psychology, 23(5), 675-696. https://doi.org/10.1521/jscp.23.5.675.50744 